\title{
OCEAN STATE ESTIMATION FOR GLOBAL OCEAN MONITORING: ENSO AND BEYOND ENSO
}

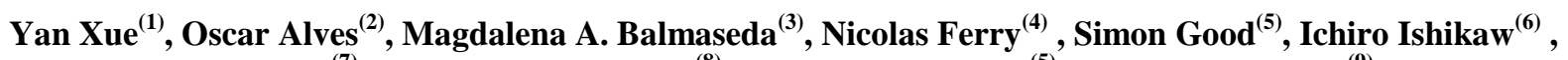 \\ Tong Lee ${ }^{(7)}$, Michael J. McPhaden ${ }^{(8)}$, K Andrew Peterson ${ }^{(5)}$, Michele Rienecker ${ }^{(9)}$ \\ (1) NOAA/NCEP (National Oceanic and Atmospheric Administration/National Centers for Environmental Prediction), \\ 5200 Auth Rd Room 605, Camp Springs, MD 20746 USA, Yan.Xue@noaa.gov \\ (2) CAWCR (Centre for Australian Weather and Climate Research), GPO Box 1289, Melbourne, VIC 3001 Australia, \\ O.Alves@bom.gov.au \\ (3) ECMWF (European Centre for Medium-Range Weather Forecasts), Shinfield Park, Reading RG2 9AX \\ United Kingdom, Magdalena.Balmaseda@ecmwf.int \\ ${ }^{(4)}$ Mercator-Océan, 8-10 rue Hermès, 31520 Ramonville, St Agne France, Nicolas.Ferry@mercator-ocean.fr \\ ${ }^{(5)}$ Met Office Hadley Centre, FitzRoy Road, Exeter, Devon, EX1 3PB United Kingdom, Simon.Good@metoffice.gov.uk, \\ Drew.Peterson@metoffice.gov.uk \\ (6) Japan Meteorological Agency, 1-3-4 Ootemachi, Chiyoda-ku, Tokyo, 100-8122 Japan, iishikawa@met.kishou.go.jp \\ (7) NASA/JPL (National Aeronautics and Space Administration/Jet Propulsion Laboratory), 4800 Oak Grove Dr., \\ Pasadena, CA 91109 USA, Tong.Lee@jpl.nasa.gov \\ ${ }^{(8)}$ NOAA/PMEL (National Oceanic and Atmospheric Administration/Pacific Marine Environment Laboratory), \\ 7600 Sand Point Way NE, Seattle, Washington 98115 USA, Michael.J.Mcphaden@noaa.gov \\ (9) NASA/GSFC/GMAO (National Aeronautics and Space Administration/Goddard Space Flight Center/Global \\ Modeling and Assimilation Office), Mail Code 610.1, Greenbelt, MD 20771 Greenbelt, MD 20771 USA, \\ Michele.Rienecker@.nasa.gov
}

\begin{abstract}
Ocean state estimation, often referred to as Ocean Reanalysis (ORA), is now routinely used for ocean initialization of seasonal forecast models and to monitor the thermal structure in the tropical Pacific. Advanced real-time ocean monitoring tools for ENSO (El Niño/Southern Oscillation) are now also being put in place. These diagnostics could potentially improve operational ENSO monitoring and forecasts by further enhancing our understanding of the physical processes in the evolution of ENSO events.

Beyond ENSO, other climate modes of variability that are of societal interest include the Indian Ocean Dipole, Tropical Atlantic Variability, and the Pacific Decadal Oscillation (PDO). Preliminary monitoring tools have also been developed for these modes. The availability of multiple ORAs provides an opportunity to assess uncertainties in the products, to help identify gaps in observing systems as they impact forecasts, identify deficiencies in data assimilation schemes. They also provide the basis for future development of multi-model ensemble monitoring products.
\end{abstract}

\section{INTRODUCTION}

Routine ocean monitoring at various operational centers has been focused primarily on monitoring the ocean thermal structure in the tropical Pacific to assist in ENSO (El Niño/Southern Oscillation) prediction. The primary tools are online plots provided at the TAO (Tropical Atmosphere Ocean) web site (http://www.pmel.noaa.gov/tao), and in-house plots derived from respective ocean state estimations, often referred as Ocean Re-Analysis (ORA). The current generation of operational ORAs, primarily developed to initialize seasonal forecast models [1], has improved in quality over those from earlier systems due to advances in data assimilation schemes, improvements in ocean modelling techniques and dramatic improvements in the global ocean observing system. ORAs are also becoming increasingly more reliable for monitoring and understanding other components of ENSO beyond its thermal structure. For example, ORAs have been used to study the equatorial Pacific mixed layer heat budgets [3] and [4], and the variability of the Pacific Subtropical Cells (STC), and relate variations to ENSO and decadal ENSO-like variability [4]. Recent deployment of the international global Argo array [5] provides an unprecedented opportunity for ORAs to assimilate salinity data, and those ORAs routinely assimilating the Argo salinity observations will be suitable for monitoring and assessing roles of salinity variability during ENSO evolution. ORAs can also be used to monitor and understand air-sea interactions during episodes of Madden Julian Oscillation (MJO) and westerly wind bursts (WWBs) and their interactions with low frequency ENSO variability [6], [7], [8], [9] and [10].

Although the initial focus of the ocean observing system and ORAs was on the ENSO monitoring and prediction, there are increasing requirements to monitor other climate modes beyond ENSO since they have significant climate impacts in different areas of the globe. For example, preliminary monitoring tools 
have been developed by the Climate Prediction Center (CPC) of National Centers for Environmental Prediction (NCEP) to monitor and assess the Indian Ocean Dipole (IOD) [11], Tropical Atlantic Variability (TAV) [12] and Pacific Decadal Oscillation (PDO) [13]. CPC provides a "Monthly Ocean Briefing" through conference call and PowerPoint Presentation (PPT), which describes how the major climate modes of variability evolved recently; what were the interactions between ocean and atmosphere; and how coupled model predictions verified (see ocean briefing PPTs at http://www.cpc.ncep.noaa.gov/products/GODAS/). Users of this product include a diverse community of operational centers, researchers, fishery managers, industries, news media, program managers, teachers and students, and are a testament of a need for ocean monitoring products beyond ENSO.

Operational ORAs have also been used to produce various climate indicators. For example, the Mercator Ocean web (http://indic.mercatorocean.fr/html/produits/indic/index_en.html) provides three indicators: sea surface temperature, sea surface salinity, and ocean heat content. For each of these indicators, several levels of information are available: geographical maps, mean value time series, and symbols representing the last 30 days trend (increase or decrease). The world ocean is divided into separate large regions: European seas, Tropical Atlantic, Tropical Pacific, and Indian Ocean. Each of them is divided further into subareas. An "Indicators Bulletin" is also being used to describe the evolution of the climate indicators in terms that are accessible to stakeholders and the general public so they can be further educated about the ocean climate.

Despite various advancements in ocean monitoring products, however, there is very little coordinated effort at the present in the operational ocean analysis community to exchange and compare ORAs (a practice that is routine in the weather prediction community). Considering that the operational ORAs are becoming increasingly more reliable, it is imperative that their utility for monitoring and understanding oceanic variability on longer time-scales, and for monitoring variables that are not routinely assimilated and/or are derived quantities is explored. The benefits of such products are potentially enormous for both the scientific community and for applications of societal interest.

Towards developing a concept for a coordinated effort based on multi-model ORAs, this paper first reviews the status of the current ORAs, and the ocean monitoring products that are being produced at seven operational centers. Section 3 discusses the applications of ORAs in the area of monitoring and understanding ENSO. Section 4 provides a view of emerging applications of ORAs in monitoring oceanic variability beyond ENSO, which includes upper ocean heat content, major climate modes and coastal upwelling. Section 5 provides some recommendations on what the operational ocean analysis community can do collectively in the production and operational implementation of some agreed upon ocean monitoring products of importance to monitor the pulse of changing climate, what the benefits of such products are, and what the requirements for ocean observing system are.

\section{THE CURRENT GLOBAL OCEAN MONITORING ACTIVITIES}

\subsection{National Centers for Environmental Prediction (NCEP), NOAA/USA}

NCEP produces ORA using the NCEP Global Ocean Data Assimilation System (GODAS) [14]. GODAS covers the 1979-present time period and is used to initialize the oceanic component of the NCEP's Climate Forecast System [15]. GODAS ocean analysis system is based on the Geophysical Fluid Dynamics Laboratory's Modular Ocean Model (MOM) version 3 in a quasi-global $\left(65^{\circ} \mathrm{S}-65^{\circ} \mathrm{N}\right)$ configuration with 40 vertical levels and a horizontal resolution of $1^{\circ} \times 1^{\circ}$ with an equatorial meridional refinement of $1 / 3^{\circ}$ resolution within $10^{\circ}$ of the equator. In operation, GODAS is updated daily with a 2-day delay, and pentad and monthly averages are used to produce ocean monitoring products. A comprehensive web site has been constructed and maintained by $\mathrm{CPC} / \mathrm{NCEP}$ in collaboration with NOAA's Office of Climate Observation (OCO) (http://www.cpc.ncep.noaa.gov/products/GODAS).

Users can find much detailed information on GODAS such as binary data link, background document, observation distributions and validation skill of GODAS against independent observations. The web site also displays numerous plots and animations about climatology and anomalies of various variables from 1979 to present.

\subsection{Global Modelling and Assimilation Office (GMAO), NASA/USA}

GMAO maintains an ocean climate monitoring page at http://gmao.gsfc.nasa.gov/cgibin/ocean/OCEAN_CLIMATE/index.cgi . Two GMAO ocean analyses are included; one from a univariate optimal interpolation (OI) that updates both temperature and salinity [16] and one from the multivariate Ensemble Kalman Filter that also assimilates along-track sea surface height anomalies from satellite altimeters [17]. The analyses, from 1993 to the present, are quasi-global (to $70^{\circ} \mathrm{N}$ ), although the ocean states are constrained by observations only from $40^{\circ} \mathrm{S}$ to $40^{\circ} \mathrm{N}$. The web site displays monthly mean fields, anomalies and tendencies from 2007 onwards, updated in the first week of each month. Fields available include sea surface temperature and salinity, sea level, zonal sections along the equator, 
the averaged temperature in the upper $300 \mathrm{~m}$, and several ocean indices.

\subsection{European Centre for Medium-Range Weather Forecasts (ECMWF)}

ECMWF (European Centre for Medium-Range Weather Forecasts) produces ORA with two streams: (i) a historical reanalysis from 1959 to present with a delay of 11 days (http://www.ecmwf.int/products/forecasts/d/charts/ocean/ reanalysis), and (ii) a real-time ocean analysis (http://www.ecmwf.int/products/forecasts/d/charts/ocean/ real time). A historical record of selected fields from the historical ORA [18] is available in the form of monthly means and hovmoeller diagrams. Spatial maps of observation coverage are also available. From January 2007 onwards, weekly averages are shown for a selection of locations and fields. Fields available include full and anomalous values of temperature, salinity, depth of $20^{\circ} \mathrm{C}$ isotherm, sea level, zonal wind stress and the averaged temperature in the upper $300 \mathrm{~m}$.

\subsection{Mercator-Ocean, France}

Mercator-Ocean delivers two ORA products: (i) one real time product used mainly for seasonal forecasting purposes and (ii) a delayed-time product (7 days behind real time). The ORA products can be seen at http://bulletin.mercator-

ocean.fr/html/produits/psy2g2/psy2g2_courant_en.jsp. PSY2G2 ORA covers the 1979-present time period and is used at Météo-France for coupled seasonal forecasts. The PSY2G2 ocean analysis system is based on OPA8.2 ocean model in a ORCA2 global configuration with 31 vertical levels and a horizontal resolution of $2^{\circ} \cos$ (lat.) x $2^{\circ}$ with an equatorial meridional refinement of $\sim 0.5^{\circ}$ resolution near the equator. In situ temperature and salinity profiles, SST maps and along track SLA data are assimilated weekly using a fixed basis reduced order Kalman filter with the SEEK formulation [19]. Real-time and delayed time anomaly maps and hovmoeller diagrams are produced and commented each month in the "Bulletin Climatologique Global" (Global Climate Bulletin) edited by Météo-France, Cerfacs and Mercator and sent to identified users.

\subsection{Met Office, United Kingdom}

The UK Met Office delivers two low-resolution ORA products. The EN3_v2a product is an objective analysis based on in situ observations only and performed on a 1 degree global grid with 42 vertical levels [20]. A historical re-analysis for the period 1950 to present is available, and the real time updates have approximately one month lag. Further information on this product (and the underlying quality controlled observations) can be found at http://hadobs.metoffice.com (Glosea4), the UK Met Office seasonal forecast system, performs a daily real time ocean analysis on a 1 degree global grid
(ORCA1). A historical ocean re-analysis for 19892002 is produced, and is expected to continue through to the present day once the system is fully implemented.

\subsection{Bureau of Meteorology (BOM), Australia}

The BOM runs two ORAs in real-time. The first one is based on in situ observations only and has been running routinely since 1988 . The analysis uses the optimal interpolation of [21] and runs twice weekly to take advantage of the most recent data, using a monthly analysis period and forecasts based on the previous month analysis and the current month climatology. In addition, a separate analysis is run for the depth of the $20^{\circ} \mathrm{C}$ isotherm in the tropical Indian and Pacific Oceans, using an analysis period of 10 days in an attempt to capture more of the higherfrequency variability. Real time analysis is available at

http://www.bom.gov.au/bmrc/ocean/results/climocan. $\underline{\mathrm{htm}}$ and a regular ENSO commentary at http://www.bom.gov.au/climate/enso .

The second analysis system is an ocean data assimilation suite primarily for initializing the Predictive Ocean Atmosphere Model for Australia (POAMA). The current system uses the optimum interpolation of [21]. A new analysis system, called PEODAS (POAMA Ensemble Ocean Data Assimilation System, http://poama.bom.gov.au/research/assim/index.htm),

has been developed and is being transitioned into operation. It is based on the multi-variant ensemble optimum interpolation of [22], but uses covariances from a time evolving model ensemble following [23]. A re-analysis from 1980 to present has been completed with this system. Both in situ temperature and salinity observations are assimilated, and current corrections are generated based on the ensemble covariances. Real-time monitoring products are being developed from this system. Heat content from the reanalysis is shown in Fig. 4.

\subsection{Japan Meteorology Agency (JMA), Japan}

JMA has been producing an ocean data assimilation system (ODAS) since 1995 for monitoring ENSO. A new system, called MOVE/MRI.COM-G [24], was implemented in March 2008. The analysis system covers the quasi-global ocean $\left(75^{\circ} \mathrm{S}-75^{\circ} \mathrm{N}\right)$, with $(0.3-1)^{\circ} \times 1^{\circ}$ grids and 50 vertical levels. It provides an ocean reanalysis from 1979 to the present with pentad and monthly outputs. Operationally, quick-look analyses with a 3-day delay and final analyses with a 39-day delay are produced. Ocean monitoring plots from the analysis are provided to the domestic users through JMA's ENSO Monitoring Bulletin (in Japanese), and to the international users through the Tokyo Climate Center web site: 
http://ds.data.jma.go.jp/tcc/tcc/products/elnino/index.htm $\underline{1}$

http://ds.data.jma.go.jp/tcc/tcc/products/clisys/index.html

Quick-look analyses are also used as initial conditions for the JMA's ENSO prediction model (JMA/MRICGCM).

\section{USE OF ORAS FOR ENSO}

\subsection{MEETING CHALLENGES FOR IMPROVING ENSO FORECASTS}

The forecast skill of ENSO has been relatively poor during the early 1990s and 2000s when SST anomalies (SSTA) were much weaker than those in the 1980s and later 1990s (Fig. 1a). Accompanying the recent changes of ENSO in the early 2000s were persistent easterly (westerly) wind anomalies in the eastern (western) tropical Pacific (Fig. 1c). Consistently, positive SSTA and heat content anomalies (HCA) persisted in the western and central Pacific. In contrast, SSTA and HCA in the eastern Pacific were dominated by weak and shortlived interannual variability. The changes in the mean background conditions appear to enhance zonaladvective feedback through an enhancement of SST gradient. Reference [26] explained the changes of ENSO in terms of coupled ocean-atmosphere modes at the ENSO (3-5 years) and sub-ENSO (1-2 years) time scales, while [27] described the changes of ENSO in terms of spatial structures and decaying mechanisms. Both of the studies suggested that the observed changes in ENSO might be explained by changes in the relative importance of zonal and vertical advection SST tendencies. Considering most numerical and statistical models are only skilful in forecasting moderate-to-strong ENSO events and perform poorly in forecasting weak and short-lived events such as those during the early 1990s and 2000s, ocean monitoring, and ORAs, are likely play a critical role in improving operational ENSO forecast by describing the complexity of physical processes that have not yet been captured by models.

Advances in ORAs, and availability of longer datasets, are also likely to improve our understanding of ENSO variability on decadal or longer time scale. For example, the changes of the mean background conditions in the early 2000 s might be related to ENSO-like interdecadal variability, which has been linked to the PDO in the North Pacific [28]. Another

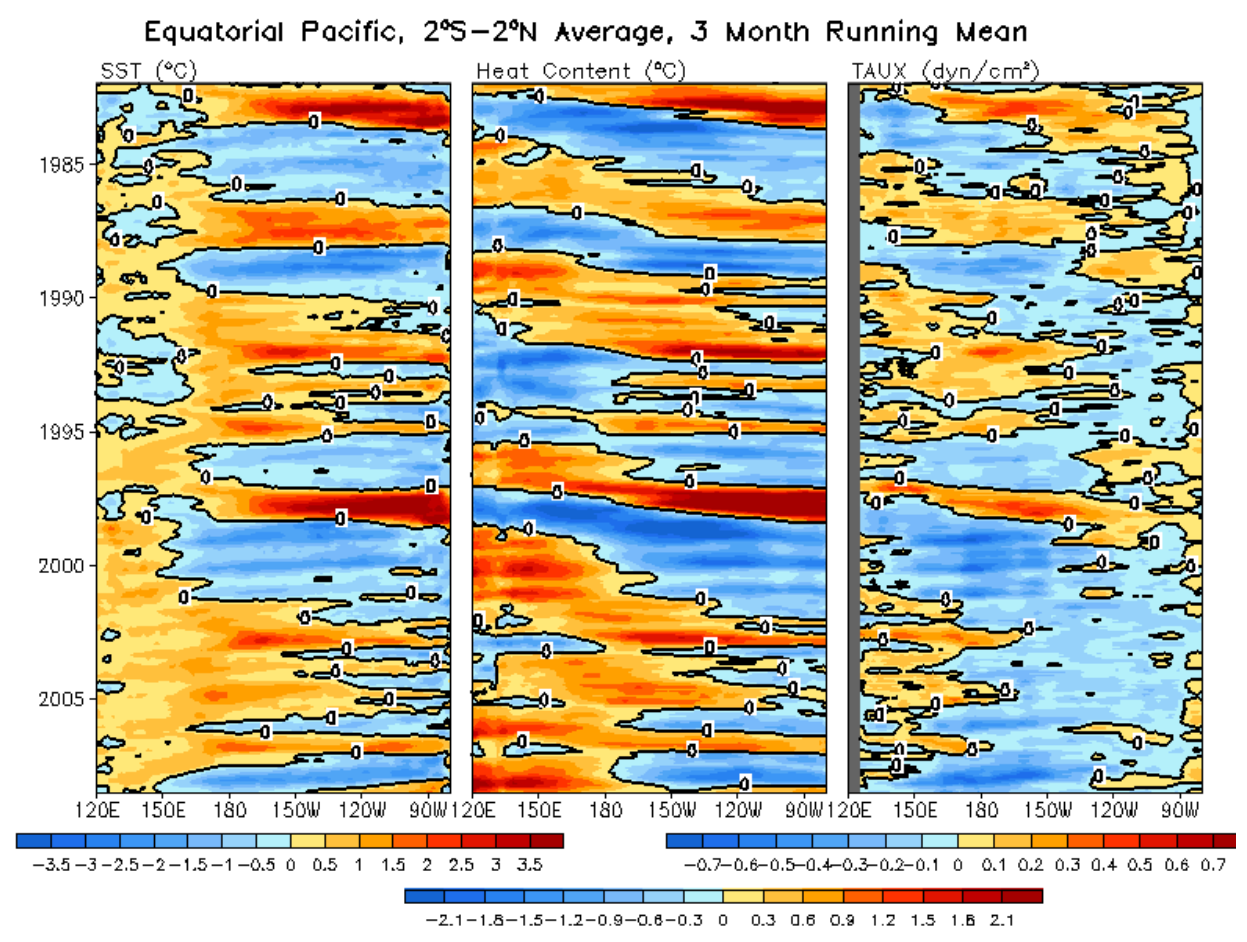

Figure 1. Time-longitude plots of 3-month-running mean of monthly SST (left), heat content (upper 300m temperature average, middle) and zonal wind stress (right) anomalies averaged in $2^{\circ} \mathrm{S}-2^{\circ} \mathrm{N}$. SSTs are from the weekly $1^{\circ} \mathrm{Optimum}$ Interpolation (OI) analyses of [25], heat contents from the NCEP GODAS, zonal wind stresses from the FSU objective wind analysis (http://www.coaps.fsu.edu/RVSMDC/html/pacmonyrq.shtml). Anomalies for SST, heat content and zonal wind stress were calculated for the base periods of 1971-2000, 1982-2004, and 1980-1995 respectively. 
hypothesis is that the low frequency variability of STC contributes to the decadal variability in the western and central tropical Pacific [29]. Different aspects of the variability of the Pacific STCs in the past few decades have been studied by, for example, [30], [4], [31], [32], and [33] using in-situ observations, satellite data, and ocean reanalysis products. In particular, [30] identified a slowdown of the STC in the past few decades, followed by a recent rebound [31]. Reference [33] described a decadal variation of the STC, characterized by a change of tendency around year 2000. Diagnostics from ORA, and associated datasets, would help further understand processes in the two competing hypotheses.
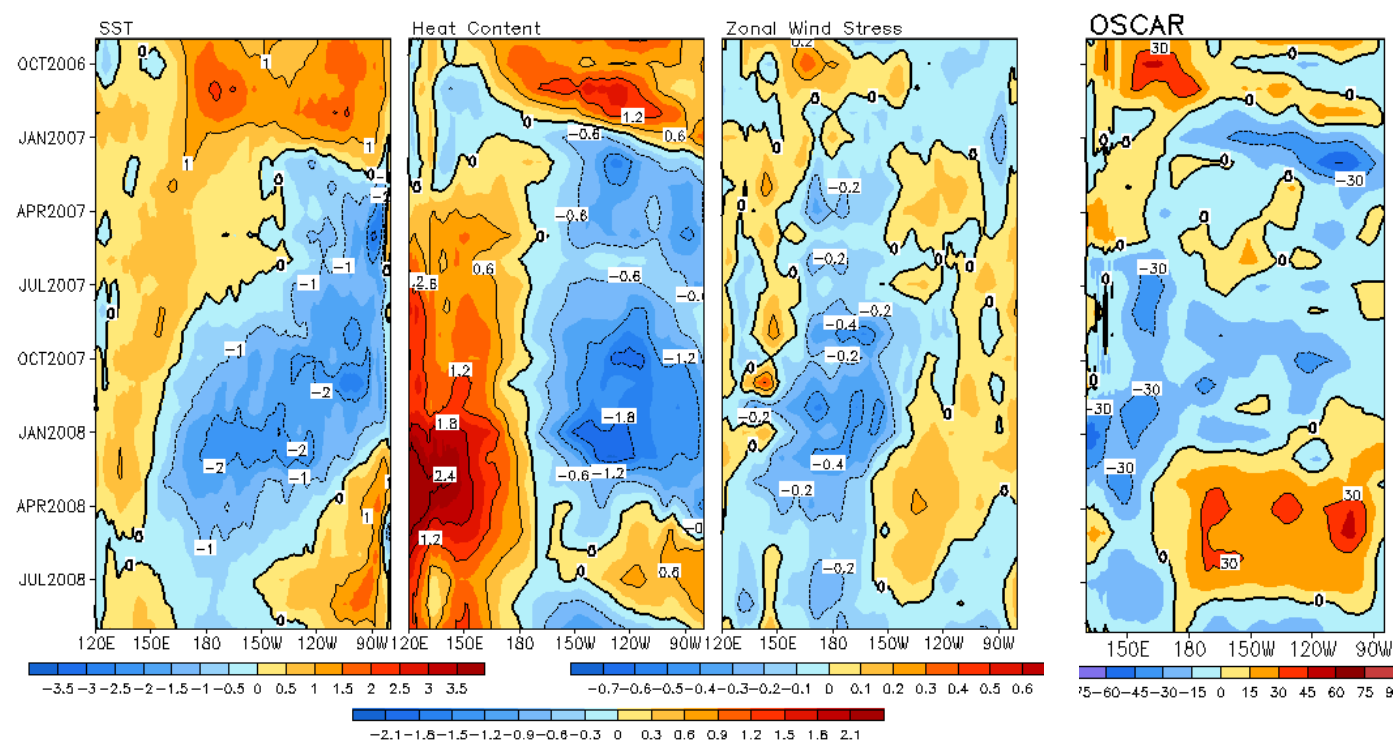

Figure 2. Time-longitude plots of monthly SST (left), heat content (upper 300m temperature average, middle-left), zonal wind stress (middle-right) and surface zonal current anomalies(right) averaged in $2^{\circ} S-2^{\circ} \mathrm{N}$. SSTs are derived from the weekly $1^{\circ}$ Optimum Interpolation (OI) analyses of [25], heat contents from the NCEP GODAS, zonal wind stresses from the NCEP Reanalysis 2 and surface zonal currents from the OSCAR currents (http://www.oscar.noaa.gov). Anomalies for SST, heat content, zonal wind stress and surface zonal current were calculated for the base periods of 1971-2000 1982-2004, 1980-1995 and 1993-2005 respectively.

\subsection{ADVANCED OCEAN MONITORING TOOLS FOR ENSO}

\subsubsection{MIXED LAYER HEAT BUDGET ANALYSIS IN REAL TIME}

Three dimensional ocean fields generated by the ORAs can also be used for development of advanced ocean monitoring products for ENSO. One such example is an operational mixed layer heat budget analysis for the tropical Pacific based on the NCEP GODAS [3]. The heat budget analysis is updated in real time along with the updates of GODAS, and the results were used to monitor and assess the evolution of the 2007/08 La Niña cycle. The La Niña started in August 2007, peaked in February 2008 with a monthly value in the NINO3.4 region of $-1.9^{\circ} \mathrm{C}$, and diminished in June 2008. Negative SSTA first appeared in the far eastern tropical Pacific in boreal spring (Fig. 2a), largely due to cooling from vertical entrainment and diffusion (Qw+Qzz) (Fig. 3c). The central Pacific SST remained near-normal until August 2007 when negative SSTA in the far eastern Pacific expanded westward. The heat budget analysis suggested that zonal advection (Qu) played the dominant role in the westward propagation of SSTA in the western and central Pacific (Fig. 3b). Note that the warming tendency of $\mathrm{Qu}$ near the Dateline was caused by biases in GODAS currents (not shown). It is interesting that surface zonal current anomaly (ZCA) switched from westward to eastward in February 08. Because of the switches of ZCA, zonal advective cooling ceased and became a warming after January 08, which contributed to a fast decline of the La Niña in spring 08. Needless to say, without the availability of ORAs development of such advanced monitoring tools would not be possible.

\subsubsection{OCEAN MONITORING BASED ON ENSO MECHANISMS}

Four conceptual oscillator models have been proposed to interpret ENSO-like oscillations: 1) the delayed oscillator [34];2) the recharge-discharge oscillator [35]; 3) the advective-reflective oscillator [36]; 4) the western Pacific oscillator [37]. Although observed ENSO-variations have elements of all the four 
conceptual models, it is difficult to quantify how each of the oscillator models contribute to the evolution of a particular ENSO cycle. Efforts have been made to explain the evolution and understand successes or failures of operational ENSO forecasts for the recent three warm events (the 1997/98, 2002/03 and 2006/07 El Niños) using some of the conceptual oscillator models [6], [38], [39]. It is found that both of the rechargedischarge oscillator and delayed oscillator contributed to the onset and decay of the three warm episodes. It is also found that atmospheric high frequency variability associated with MJO and WWB influenced the timing and amplitude of the three El Niño events significantly. To get a more accurate assessment of ENSO evolution and to anticipate its future development, it is critical to monitor all aspects of atmospheric and oceanic variability associated with different mechanisms discussed above, a goal that could be greatly facilitated by the availability of multiple ORAs. (a) $\mathrm{Tt}, \mathrm{Eq}$

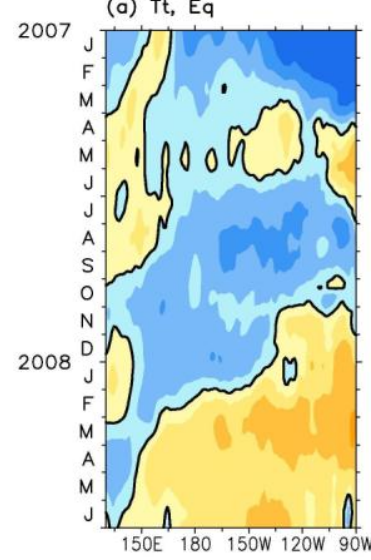

(b) Qu

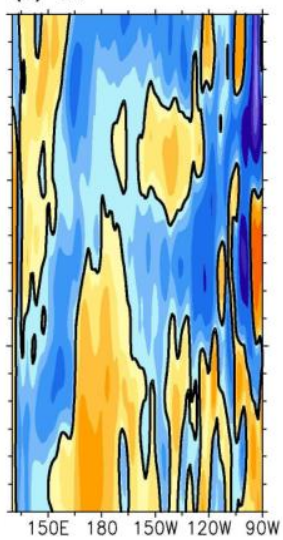

(c) $Q w+Q z z$

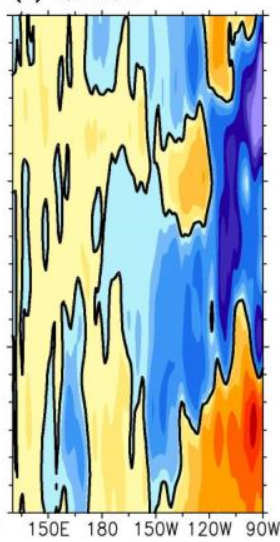

(d) Qq

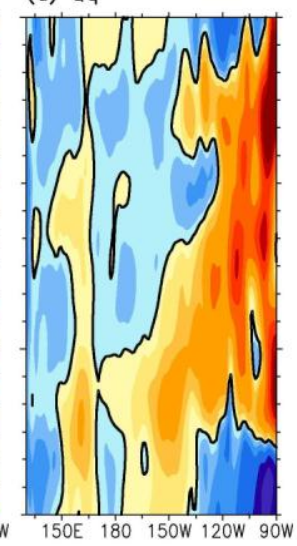

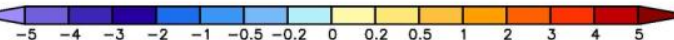

Figure 3. Time-longitude plots of (a) anomalous temperature tendency, (b) anomalous zonal advection, (c) anomalous vertical entrainment and diffusion, and $(d)$ anomalous adjusted surface heat fluxes along the equator.

\section{LOOKING BEYOND ENSO}

\subsection{UPPER OCEAN HEAT CONTENT VARIABILITY}

The availability of several real-time operational ORA products would allow routine monitoring of other climate indices. As an example, Fig. 4 shows time series of a proxy for upper ocean heat content anomalies (averaged temperature anomalies in the upper $300 \mathrm{~m}$ ) in selected areas from 1985 to present. The anomalies were based upon the 1985-2005 climatology and smoothed with a 12-month running mean. Shown are operational ORAs from six institutions: NCEP, ECMWF, Mercator Ocean (mctr), BOM, JMA, and GMAO (see Sect. 2 for details). In addition, the EN3_v1c objective ocean analysis produced by the Met Office is shown (meto). EN3_v1c is a predecessor to EN3_v2a, which was described in Sect. 2. The faulty SOLO-FSI Argo sensors were excluded from the EN3 analyses. Time-varying corrections to expendable bathythermograph (XBT) data, such as those proposed by [40], are not yet incorporated.

The comparison shown in Fig. 4 is not an operational activity yet: it is only an example of the unexploited potential of the existing operational products. Upper ocean heat content anomalies should complement the climate monitoring currently done with SST indices. For instance, Fig. 4 shows that all ORA products indicate that the negative phase of the Indian Ocean Dipole is weakening from peak negative values in 2008. The North Subtropical Atlantic (NSTRATL) shows a pronounced decadal variability, relatively coherent among the different products; most of the re-analyses indicate a downward trend from the unusually (record-high) warm conditions in 2005 to near nearnormal conditions in 2009. Interestingly, the spread of the products appears expanded during the recent years when observations are relatively plentiful due to the Argo array. The North Atlantic (NATL) had a rapid warming during the 1990s and then stabilized on values reached in 2000 s, with some variabilities at interannual time scales.

The spread among the indices can be taken as a measure of uncertainty in our knowledge of the climate. The uncertainty of some indices is larger than others: the interannual variability of the Indian Ocean Dipole and the decadal variability of the subtropical North Atlantic seem to be robust among ORAs. All the ORAs also show the warming trends in the North Atlantic, and global ocean, but there seem to be uncertainty on the magnitude of the trend. The uncertainty is large in the latter years. Reducing the uncertainty in the estimation of climate indices should 
be a target for the community in the years to come. Interestingly, the objective ocean analysis based on observations only (meto) remains quite near the centre of the distribution of ORA values. This can be taken as an indication that a large source of the uncertainty resides in the re-analysis system (ocean model, forcing fluxes, quality control of observations and assimilation methodology).

\subsection{IOD}

The Indian Ocean Dipole Mode, characterized by anomalously cold (warm) SST in the southeast (western)
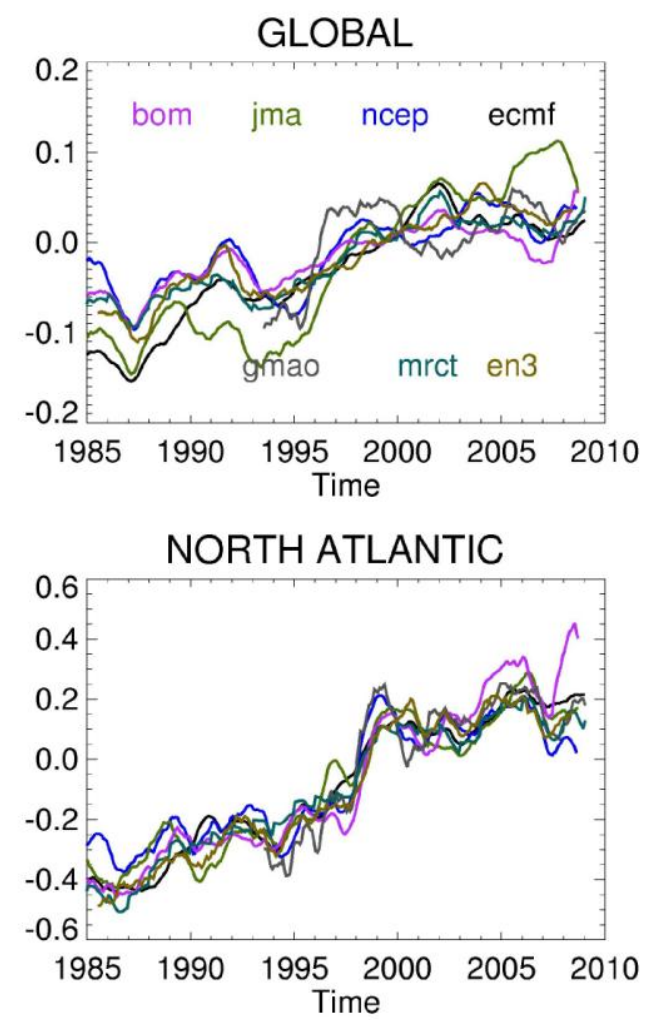

equatorial Indian Ocean, is the strongest mode of variability in the Indian Ocean sector on interannual time scales [41]. ORA products have been used to study mixed-layer heat balance associated with IOD [42], [43] and to contrast the behaviour of previous IOD events [43]. The frequent occurrence of IOD (or IOD-like) events in the past few years has been an interesting phenomenon that needs to be understood. ORA products, once again, are essential to monitor the evolution of mixed-layer heat budget in real time similar to the monitoring of ENSO events.
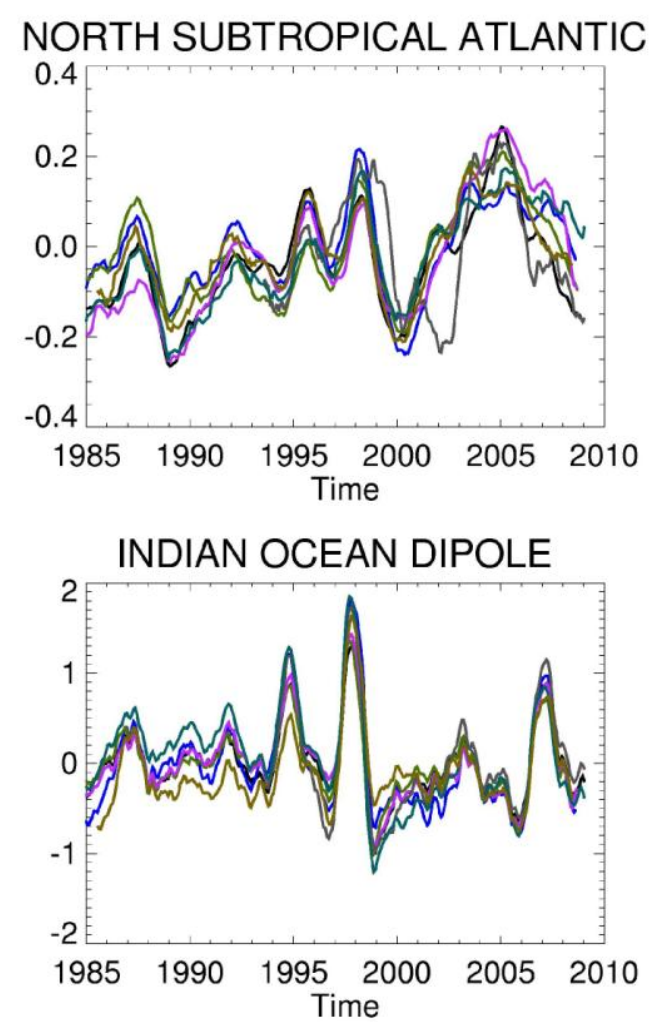

Figure 4. Time series of averaged temperature anomalies in the upper 300m in selected areas from 1985 to present. Seven real-time operational ocean reanalysis are shown: NCEP GODAS, BOM POAMA, JMA, ECMWF (ORA-S3), Mercator PSY2G2 (mrct), NASA GMAO, and the UK Met Office objective ocean analysis EN3_vlc (meto).

\subsection{PDO}

The Pacific Decadal Oscillation (PDO) [13] also referred to as the Interdecadal Pacific Oscillation [44], is a prominent mode of decadal time scale variability that spans both hemispheres of the Pacific basin. It has a spatial structure very similar to that of ENSO and is sometimes referred to as ENSO-like decadal variability. As with ENSO, the PDO has substantial effects on climate and Pacific marine ecosystems. The dynamics of the PDO are much less well understood than those of ENSO, however, and there is considerable debate about the underlying physical processes that govern them [45]. ORA products can be used to monitor the ocean currents, temperature and salinity structures during the evolution of the PDO, and to understand its connection with ENSO variability.

\subsection{COASTAL UPWELLING}

Coastal upwelling is an indicator for the primary productivity, and ORA products can be used to monitor coastal upwelling for benefits of fisheries and marine ecosystem communities. Once such example is the experimental coastal upwelling index derived from the NCEP GODAS, and the results are delivered to the public through the GODAS web site and "Monthly Ocean Briefing" at CPC/NCEP. 


\subsection{NORTH ATLANTIC AND EUROPEAN REGIONAL SEAS}

The North Atlantic Oscillation (NAO) has contributed to a long-term trend in the North Atlantic upper ocean heat content and Western Mediterranean Deep Water [46]. The need for enhanced detection and assessment of the impacts of climate change on the European seas is well recognised (see Impacts of Europe's changing climate, European Environmental Agency, September 2008). The diverse nature of Europe's regional seas represents a particular challenge for monitoring and management of climate change at the Pan-European, regional and local levels. The assessment of future climate trends and impacts could take advantage of multiple ORAs products and new ocean monitoring strategies.

\section{THE FUTURE}

The ocean community now stands at a cusp of opportunity where enhanced coordination among different operational centers would greatly benefit the scope of the ocean monitoring products extending from interannual to decadal and longer time-scales, and from regional to global spatial scales. Such an advancement and coordination is essential to demonstrate benefits of investments already made in the development of the ocean observing system, and to also justify future investments in either sustaining or building upon the current ocean observing system that is in place.

Looking to the future and towards enhancing the scope of ocean monitoring products based on multiple ORAs, the following initial list of ocean monitoring products is recommended:

- Monitoring upper ocean heat content variability, particularly those associated with all major climate modes (ENSO, IOD, PDO, TAV, etc.);

- Developing advanced diagnostic tools such as mixed layer heat budget analysis for monitoring the physical processes for all major climate modes in near real time;

- Monitoring and validating real time forecasts from seasonal forecast models beyond SST;

- Monitoring global sea surface salinity variability derived from operational ORAs to compare with data anticipated from SMOS and Aquarius;

- Developing climate indices that would help attribution of climate variations, and even provide information on ocean variations that are precursors to climate variations of societal importance such as changes in coastal upwelling, precipitation and extreme weather events such as tropical storms and hurricanes/cyclones/typhoons.
- Developing climate indices using multi-model ensemble ORAs to provide a level of confidence in various ocean products or in the diagnostics of a particular "ocean climate event";

- Assessing differences among multi-model ensemble ORAs to help with future development of the ocean observing system: Are there any discontinuity in the observational data streams? Do the analyses accept the data? Is the global coverage adequate or regional gap exists? Are there any changes in time in how the data is accepted?

- Monitoring the differences among multi-model ensemble ORAs to help identify common biases / deficiencies in ORA products and possibly better understand the origin of large / weak dispersion in the multi-model climate indicators;

- Observational errors do contribute to the spread among the ORA products and more effort is needed in comparing data quality control;

- The scope of ocean products based on the ORA also needs to expand beyond the physical variables to include connection with oceanic biological and chemical measurements; ecosystems and fisheries management, and of the monitoring of the health of the oceans. Such an effort would be critical for translating benefits of investments in the ocean observing system to different aspects that are of critical societal relevance.

Finally, since the real-time operational ORAs are more likely to be affected by observational errors and changes in the observing system, we need to emphasize the "stability" and "accuracy" of the observing system so that impact of observational errors and changes in the observing system on the inferred variability in the climate indices is minimized. So we highly recommend, 1) the tropical moored buoy arrays are maintained and even expanded since the information they provide are critical for constraining model biases, particularly in the eastern tropical Pacific, the tropical Indian and Atlantic Oceans, and improving understanding and forecasting of the tropical climate variability; 2) satellite altimetry is maintained to give high temporal and spatial resolution of anomalies off the equator; 3) Argo is maintained for the important information it gives especially on ocean salinity, 4) information from surface flux moorings are maintained to help calibrate satellite observations and correct biases in atmospheric analyses.

\section{REFERENCES}

1. Balmaseda, M. \& Co-Authors (2010). "Initialization for Seasonal and Decadal Forecasts" in these proceedings (Vol. 2), doi:10.5270/OceanObs09.cwp.02. 
2. Kim, S.-B., T. Lee and I. Fukumori, 2007: Mechanisms controlling the interannual variation of mixed layer temperature averaged over the NINO3 region. $J$. Clim., 20, 3822-3843.

3. Huang, B., Y. Xue, X. Zhang, A. Kumar and M. J. McPhaden, 2009: The NCEP GODAS ocean analysis of the tropical Pacific mixed layer heat budget on seasonal to interannual time scales, Submitted to $J$. Clim.

4. Lee, T., and I. Fukumori, 2003: Interannual to decadal variation of tropical-subtropical exchange in the Pacific Ocean: boundary versus interior pycnocline transports. J. Clim., 16, 4022-4042.

5. Freeland, H. \& Co-Authors (2010). "Argo - A Decade of Progress" in these proceedings (Vol. 2), doi:10.5270/OceanObs09.cwp.32.

6. McPhaden, M. J. and Yu, X., 1999: Equatorial waves and the 1997-98 El Niño, Geophys. Res. Lett., 26, 29612964.

7. Vecchi, G. A. and Harrison, D. E., 2000: Tropical Pacific sea surface temperature anomalies, El Niño, and equatorial westerly wind events, J. Climate, 13, 18141830.

8. Kessler, W. S. and Kleeman, R., 2000: Rectification of the Madden-Julian oscillation into the ENSO cycle, $J$. Climate, 13, 3560-3575.

9. Seo, K.-H., and Y. Xue, 2005: MJO-related oceanic Kelvin waves and the ENSO cycle: A study with the NCEP Global Ocean Data Assimilation System. . Geophys. Res. Lett., 32, L07712, doi:10.1029/2005GL022511.

10. Hendon, H. H., Wheeler, M. C. and Zhang, C., 2007 Seasonal Dependence of the MJO-ENSO Relationship, J. Clim., 20, 531-543.

11. Saji, N. H., Goswami, B. N., Vinayachandran, P. N. and Yamagata, T., 1999: A dipole mode in the tropical Indian Ocean, Nature, 401, 360-363.

12. Chang, P. and Coauthors, 2006: Climate fluctuations of tropical coupled systems-The role of ocean dynamics. J. Clim., 19, 5122-5174.

13. Mantua, N. J., Hare, S. J., Zhang, Y., Wallace, J. M. and Francis, R. C., 1997: A Pacific interdecadal oscillation with impacts on salmon production, B. Am. Meteorol. Soc., 78, 1069-1079.

14. Behringer, D. W. and Y. Xue, 2004: Evaluation of the global ocean data assimilation system at NCEP: The Pacific Ocean, Eighth Symposium on Integrated Observing and Assimilation System for Atmosphere, Ocean, and Land Surface, AMS 84th Annual Meeting, Washington State Convention and Trade Center, Seattle, Washington, 11-15.

15. Saha S. and Coauthors, 2006: The NCEP Climate Forecast System. J. Clim., 19, 3483-3517.
16. Sun, C., M. M. Rienecker, A. Rosati, M. Harrison, A. Wittenberg, C. L. Keppenne, J. P. Jacob and R. M. Kovach, 2007: Comparison and sensitivity of ODASI ocean analyses in the tropical Pacific. Mon. Wea. Rev., 135, 2242-2264.

17. Keppenne, C.L., M.M. Rienecker, J.P. Jacob and R. Kovach, 2008: Error covariance modeling in the GMAO ocean ensemble Kalman filter. Mon. Wea. Rev., 136, 2964-2982.

18. Balmaseda, M.A., Arthur Vidard and David Anderson, 2008: The ECMWF ORA-S3 ocean analysis system. Mon. Wea. Rev, 136, 3018-3034.

19. Drévillon, M., R.Bourdalle-Badie, C. Derval, Y. Drillet, J.-M. Lellouche, E. Remy, B. Tranchant, M. Benkiran, E. Greiner, S. Guinehut, N. Verbrugge, G. Garric, C.E. Testut, M. Laborie, L. Nouel, P. Bahurel, C. Bricaud, L. Crosnier, E. Dombrowsky, E. Durand, N. Ferry, F. Hernandez, O. Le Galloudec, F. Messal and L. Parent, 2008: The GODAE/Mercator-Ocean global ocean forecasting system: results, applications and prospects. J. of Operational Oceanography, 1, 51-57.

20. Ingleby, B. and M. Huddleston, 2007: Quality control of ocean temperature and salinity profiles - historical and real-time data. Journal of Marine Systems, $\mathbf{6 5}, 158$ 175 .

21. Smith, N. R., J. E. Blomley and G. Meyers, 1991: A univariate statistical interpolation scheme for subsurface thermal analyses in the tropical oceans. Prog. Oceanog., 28, 219-256.

22. Oke, P. R., A. Schiller, D. A. Griffin and G. B. Brassington, 2005: Ensemble data assimilation for an eddy-resolving ocean model of the Australian region. Q. J. Roy. Met. Soc., 131, 3301-3311.

23. Alves. O. and C. Robert, 2005: Tropical Pacific ocean model error covariances from Monte Carlo simulations. Q. J. R. Meteorol. Soc., 131, 3643-3658.

24. Usui, N., S. Ishizaki, Y. Fujii, H. Tsujino, T. Yasuda and M. Kamachi, 2006: Meteorological Research Institute Multivariate Ocean Variational Estimation (MOVE) System: Some early results. Adv. Spa. Res., 37, 806822.

25. Reynolds, R. W., N. A. Rayner, T. M. Smith, D. C. Stokes and W. Wang, 2002: An improved in situ and satellite SST analysis for climate, J. Climate, $\mathbf{1 5}$, 1609-1625.

26. Keenlyside, N.S. and M. Latif, 2007: On Sub-ENSO Variability. J. Climate, 20, 3452-3469.

27. Kug, J.-S., F.-F. Jin and S.-I. An, 2009: Two types of El Nino events: Cold tongue El Nino and warm pool El Nino. J. Clim., 22, 1499-1515.

28. Zhang, Y., J. M. Wallace and D. S. Battisti, 1997: ENSO-like interdecadal variability: 1900-93. $J$. Climate, 10, 1004-1020. 
29. Lohmann, K. and M. Latif, 2005: Tropical Pacific decadal variability and the Subtropical-tropical Cells. J. Clim., 18, 5163-5178.

30. McPhaden, M. J. and D. Zhang, 2002: Slowdown of the meridional overturning circulation in the upper Pacific Ocean, Nature, 415, 603-608.

31. McPhaden, M. J. and D. Zhang, 2004: Pacific Ocean circulation rebounds, Geophys. Res. Lett., 31, L18301, doi:10.1029/2004GL020727.

32. Schott, F.A., W.-Q. Wang and D. Stammer, 2007: Variability of Pacific subtropical cells in the 50-year ECCO assimilation. Geophys. Res. Lett., 34, L05604, doi:10.1029/2006GL028478.

33. Lee, T. and M.J. McPhaden, 2008: Decadal phase change in large-scale sea level and winds in the IndoPacific region at the end of the $20^{\text {th }}$ century. Geophys. Res. Lett., 35, L01605, doi:10.1029/2007GL032419.

34. Schopf, P. S. and Suarez, M. J., 1988: Vacillations in a coupled ocean-atmosphere model, J. Atmos. Sci., 45, 549-566.

35. Jin, F.-F., 1997: An equatorial ocean recharge paradigm for ENSO. Part I: Conceptual model, J. Atmos. Sci., $\mathbf{5 4}, 811-829$.

36. Picaut, J, M. Ioualalen, C. Menkes, T. Delcroix and M. J. McPhaden, 1996: Mechanism of the zonal displacements of the Pacific Warm Pool: Implications for ENSO, Science, 29.

37. Weisberg, R. H. and Wang, C., 1997: A western Pacific oscillator paradigm for the El Niño-Southern Oscillation, Geophys. Res. Lett., 24, 779-782.

38. McPhaden, M.J., 2004: Evolution of the 2002-03 El Niño. Bull. Amer. Meteor. Soc., 85, 677-695.

39. McPhaden, M.J., 2008: Evolution of the 2006-2007 El Nino: the role of intraseasonal to interannual time scale dynamics. Adv. Geosci., 14, 1-12.

40. Wijffels, S.E., J. Willis, C.M. Domingues, P. Barker, N.J. White, A. Gronell, K. Ridgway and J.A. Church, 2008: Changing expendable bathythermograph fall rates and their impact on estimates of thermosteric sea level rise, J. Clim. 21, 5657-5672.

41. Saji, N. H., Goswami, B. N., Vinayachandran, P. N. and Yamagata, T., 1999: A dipole mode in the tropical Indian Ocean, Nature, 401, 360-363.

42. Du, Y, T.-D. Qu and G. Meyers, 2008: Interannual variability of sea surface temperature off Java and Sumatra in a global GCM. J. Clim., 21, 2451-2465.

43. Halkides, D. and T. Lee, 2009: Mechanisms controlling seasonal-to-interannual mixed-layer temperature variability in the southeastern tropical Indian Ocean. $J$. Geophys. Res., 114, C02012, doi:10.1029/2008JC004949.

44. Power, S., M. Haylock, R. Colman and X. Wang, 2006: The Predictability of Interdecadal Changes in ENSO Activity and ENSO Teleconnections. J. Clim., 19, 4755-4771.
45. Miller, A. J. \& Schneider, N., 2000: Interdecadal climate regime dynamics in the North Pacific Ocean: theories, observations, and ecosystem impacts. Prog. Oceanogr. 47, 355-379.

46. Rixen, M., et al. (2005), The Western Mediterranean Deep Water: A proxy for climate change, Geophys. Res. Lett., 32, L12608, doi:10.1029/2005GL022702 